\title{
Prospective Evaluation of Surgical Management Strategy of Thyroid Diseases in Assiut University Hospitals, A Clinical Audit
}

\author{
FAROUK A. MOURAD, M.D.; MOSTAFA A. HAMAD, M.D. and AHMED A. GAD, M.Sc.
}

The Department of General Surgery, Faculty of Medicine, Assiut University, Assiut, Egypt

\begin{abstract}
Background: Thyroid surgery is the mainstay of the treatment of surgical goiters. Treatment modalities for the surgical management of goiter include lobectomy, sub-total thyroidectomy, near-total thyroidectomy and total thyroidectomy.
\end{abstract}

Aim of Study: To compare current surgical management of thyroid diseases in Assuit University Hospital with management guidelines, planning for improving our management of thyroid diseases and correct obstacles to achieve reduction in the morbidity and mortality result from thyroid diseases.

Patients and Methods: Our study included 60 patients who were admitted to General Surgery Department with any thyroid disease during a period of six months and managed surgically. All patients had neck ultrasound and FNAC was done for suspicious cases for malignancy. Benign solitary nodular goiter was managed by unilateral lobectomy and isthmusectomy. MNG was managed by total and sub-total throidectomy. Malignant goiter was managed according to cytology with total thyroidectomy being done for most cases. Controlled toxic goiter was managed by total or sub-total thyroidectomy. All cases were subjected to pre-and postoperative layrngoscopic examination for assessement of vocal cord mobility. Post-operative histopathology is amust in all cases.

Results: Mean age of the studied patients was $39.18 \pm 11.75$ years with range between 15 and 63 years. Out of 60 patients, $49(81.7 \%)$ patients were females and $11(18.3 \%)$ patients were males. 17 (28.3\%) of the studied had toxic manifestations and $15(25 \%)$ patients were on anti-thyroid medications. Iodine deficiency was noticed in $9(15 \%)$ patients while 7 $(11.7 \%)$ patients had endemic goiter. Out of the studied patients, $5(8.3 \%)$ patients had family history of thyroid disease.

Unilobar enlargement presented in $12(20 \%)$ patients while $48(80 \%)$ patients had Bilobar thyroid enlargement. Diffuse goiter presented in $4(6.7 \%)$ patients and nodular goiter in $56(93.3 \%)$ patients, $13(21.7 \%)$ solit all patients were subjected to thyroid function tests (TSH, free T3 and T4) before and after thyroidectomy. It was noticed that there were significant improvement in level of TSH, free T3 and free T4 after thyroidectomy $(p<0.05)$.

Correspondence to: Dr. Ahmed A. Gad, E-Mail: Ahmeddeek2020@gmail.com
FNAC was done in $41(68.3 \%)$ patients. Total thyroidectomy was performed in $43(71.7 \%)$ patients while $10(16.7 \%)$ and $7(11.7 \%)$ patients had subtotal thyroidectomy and unilateral lobectomy with isthmusectomy respectively. The most frequent complications post-operatively were hoarseness of the voice and choking occurred in $18(30 \%)$ and $16(26.7 \%)$ patients respectively. Injury of RLN occurred in $5(8.3 \%)$ patients.

All of those patients received replacement therapy and none of them received chemotherapy or iodine therapy.

Post-operative complications were frequent in those patients had total thyroidectomy where hoarseness of the voice, chocking and injury of recurrent laryngeal nerve occurred in $13(30.2 \%), 12(27.9 \%)$ and $5(11.6 \%)$ patients respectively.

In case of subtotal thyroidectomy 4 (40\%) patients had choking and $4(40 \%)$ patients had hoarseness of the voice. Only one patient from those had unilateral thyroidectomy had post-operative complication in form of hoarseness of the voice.

Duration of surgeon experience was less than 5 years in majority of cases $(56.7 \%)$ while in $16(26.7 \%)$ and $10(16.7 \%)$ patients duration of surgeon experience was 5-10 and more than 10 years respectively. With experience less than 5 years, post-operative complications were; 3 patients had R.L.N. injury, 12 patients had hoarseness of voice, and 10 patients had chocking. With surgical experience between 5 to 10 years, complications were; 2 patients had R.L.N. injury, 4 patients had hoarseness of voice, and 5 patients had chocking. While with experience more than 10 years, the complications were so minimal with only 2 patients had transient hoarseness of voice and chocking.

In case of controlled toxic goiter; $15(75 \%), 3(15 \%)$ and $2(10 \%)$ patients had total, subtotal and unilateral thyroidectomy respectively. In case of simple goiter; 7 (58.3\%) patients had total thyroidectomy, $4(8.3 \%)$ patients had unilateral thyroidectomy and $1(8.3 \%)$ patient had subtotal thyroidectomy.

$21(75 \%)$ patients from those with multinodular goiter had total thyroidectomy, $6(21.4 \%)$ had subtotal thyroidectomy and $1(3.6 \%)$ patient had unilateral thyroidectomy.
Abbreviations:
MNG : Mutinodular Goiter.
RLN : Recurrent Laryngeal Nerve.
FNAC : Fine Needle Aspiration Cytology.
$\mathrm{U} / \mathrm{S}$ : Ultrasound 
Conclusion: In our study, no major difference was noticed between our surigal management strategy of thyroid diseases and international guidelines. Pre-operative assessement was focused with neck U/S and FNAC being the most important investigations. Choice of the type of operation was based on the type of thyroid disease and the risk of post-operative complications was considered.post-operative complications in the form of RLN injury, hypothyroidism and hypoparathyroidism were markedly decreased.

Key Words: Thyroid surgery - Thyroid guidelines - Goiter.

\section{Introduction}

THYROID disorders are 5-10 times less common in men and can present at any age [1]. Thyroid surgery has been reported to be the mainstay of the treatment of surgical goiters [2].

Surgical management is recommended for goiters with compressive symptoms. Symptoms of dyspnea, orthopnea, and dysphagia are more commonly associated with goiter, in particular, substernal goiters. Treatment modalities for the surgical management of goiter include lobectomy, sub-total thyroidectomy, near-total thyroidectomy and total thyroidectomy $[3,4]$.

Total thyroidectomy is the gold standard treatment for thyroid cancer, multi-nodular goitre and grave's disease, but with high risk of postoperative complications (transient or permanent hypocalcaemia and recurrent laryngeal nerve palsy) [5,6].

Subtotal thyroidectomy has low incidence of post-operative complications, but recurrence rates as high as $45 \%$. Near-total thyroidectomy is a safe option for various benign thyroid diseases, with both low recurrence and complication rates when compared with total thyroidectomy $[\mathbf{7 , 8 ]}$.

Most surgeons prefer to perform lobectomy or subtotal thyroidectomy for such benign conditions as nodular goiter, thyroiditis, and hyperthyroidism even when they have to leave grossly abnormal tissue in the neck owing to the complication rate associated with this procedure $[\mathbf{9 , 1 0 ]}$.

\section{Subjects and Methods}

All patients with thyroid diseases admitted and managed surgically in General Surgery Department in Assiut University Hospital between June 2017 to December 2017.

\section{Exclusion criteria:}

Patients who were admitted to General Surgery Department in Assiut University Hospital and not managed surgically during the study period.
Methods: All the patients had been subjected to the following:

\section{1- Pre-operative assessment:}

- Full clinical assessment.

- Routine laboratory studies.

- Thyroid profile.

- Neck ultrasonography; for detection of gland consistency, retrosternal extension, tracheal deviation, and cervical lymphadenopathy.

- Thyroid scan when indicated; was done for detection of the nature of the nodules (hotwarm-cold).

- Fine Needle Aspiration Cytology (FNAC); when indicated (cold nodule on thyroid scan or dominant one of multi nodular goitre or solitary thyroid nodule).

- Referral to ENT specialist; for indirect laryngoscopy to determine the mobility of the vocal folds.

All the patients were informed that they have to take post-operative medications (hormonal replacement). All patients were informed about all possible complications of thyroidectomy.

\section{2- Standard guidelines for surgical management} of thyroid diseases were reviewed:

1- Surgical management of differentiated thyroid cancer: (ATA guidelines 2016): $85 \%$ of patients with differentiated thyroid carcinomas are cured with surgery, radioactive iodine, and TSH suppression.

\section{Thyroid surgery for papillary thyroid carcinoma:}

Total thyroidectomy for large tumours or tumours of any size with additional risk factors has been shown to be associated with fewer recurrences and better survival. For patients with tumours $4 \mathrm{~cm}$ or smaller and no risk factors, hemithyroidectomy without Radioiodine Remnant Ablation (RRA) is reported to have an equally favourable outcome to total thyroidectomy, though all studies are retrospective. This could apply to non-invasive encapsulated (or partly encapsulated) Follicular Variant Papillary Thyroid Cancer (FVPTC).

Patients with "radiation-induced" thyroid cancer appear to present with more advanced disease, but there is conflicting evidence as to whether outcome or cause specific survival is worse or no different from patients without prior irradiation. 
Surgery for follicular thyroid carcinoma (excluding oncocytic (Hürthle Cell) follicular carcinoma):

I- If definitive histology reveals a follicular adenoma or a hyperplastic nodule, no further treatment is required.

II- Patients with follicular cancer $>4 \mathrm{~cm}$ tumours appear to have worse prognosis and should be treated with total thyroidectomy.

III- Patients with tumours $<4 \mathrm{~cm}$, in the absence of other adverse risk factors (age $>45$ years, widely invasive, lymph node/distant metastases, angioinvasion) appear to have an excellent prognosis. It is recommended that such patients may be treated with hemithyroidectomy.

IV-Patients with tumours $>1-<4 \mathrm{~cm}$ and adverse risk factors (age $>45$ years, widely invasive, lymph node/distant metastases, angioinvasion) should be treated with total thyroidectomy.

V- Lymph node metastasis from follicular thyroid cancer is found in $1 \%-8 \%$ of patients. If there is pre-operative or intra-operative suspicion of nodal disease, FNAC or frozen section should be performed prior to therapeutic node dissection.

Surgery for oncocytic (Hürthle Cell) follicular carcinoma:

There is conflicting evidence as to whether Hürthle cell carcinoma has equivalent or worse prognosis compared with follicular thyroid cancer, and worse prognosis compared with other types of DTC. Lymph node metastases are reported to occur in $3 \%-25 \%$ of cases, tumour size $(>5 \mathrm{~cm})$ and older age ( $>80$ years) are risk factors for nodal disease. Hürthle cell tumours are less likely to concentrate I131.

I- Total thyroidectomy is recommended for oncocytic (Hürthle cell) carcinomas $>1 \mathrm{~cm}$ in diameter.

II- Patients with oncocytic (Hürthle cell) microcarcinoma (tumour size $<1 \mathrm{~cm}$ ) are reported to have an increased risk of distant metastases and reduced disease specific survival compared with patients with microPTC. Also no survival benefit was identified for patients who underwent total thyroidectomy compared with patients treated with hemithyroidectomy. For patients with oncocytic (Hürthle cell) microcarcinoma personalised decision making about hemi-or total thyroidectomy is recommended.

III- Therapeutic lymph node dissection should be performed in patients with clinical and/or radi- ological evidence of lymph node involvement and pathological confirmation of metastasis.

\section{Long-term follow-up of differentiated thyroid} cancer:

The long-term follow-up schedule of patients with a previous diagnosis of Differentiated Thyroid Cancer (DTC) depends on risk.

I- Patients who have undergone hemithyroidectomy alone because of the low risk of recurrence do not require TSH suppression or long-term follow-up in secondary care. For all other patients, regular follow-up of DTC is necessary particularly for detection of early recurrence, initiation of appropriate treatment, TSH suppression and management of hypocalcaemia.

II- Once the thyroid remnant has been ablated and following dynamic risk stratification, the frequency of attendance will be decided in each case individually:

- Patients with excellent response should be followed 6 monthly for the first year, and annually thereafter.

- Patients with indeterminate or incomplete response should be followed-up more frequently depending on individual need.

III- Support and counseling may be necessary, particularly for younger patients, and in relation to pregnancy.

$I V$ - Follow-up should be lifelong for the following reasons:

- The disease has a long natural history.

- Late recurrences can occur, which can be successfully treated with a view to cure or long-term survival.

- The consequences of supraphysiological levothyroxine replacement (such as atrial fibrillation and osteoporosis) need monitoring, especially as the patient ages.

- Late side effects of I131 treatment may develop, such as leukaemia or second tumours.

V- Low-risk cases who have completed their treatment, are shown to be free of disease at five years and no longer judged to require TSH suppression, may be followed-up at outpatient clinic.

At each visit the following tasks should be completed:

- Patient history should be taken.

- A clinical examination should be performed. 
- Adequacy of TSH suppression and possible effects of thyrotoxicosis should be assessed.

- Tg should be measured as a marker of tumour recurrence. $\mathrm{TgAb}$ should be measured simultaneously with measurement of $\mathrm{Tg}$.

- The calcium status should be assessed in patients receiving treatment for hypoparathyroidism.

\section{2- Surgical management of Medullary thyroid} cancer (British Thyroid Association guidelines 2015):

- All patients with or, at risk of MTC should be referred for investigation/surgical treatment to a cancer centre.

- In all cases, a comprehensive family history must be taken to include first- and second-degree relatives to search for features of MTC or other endocrinopathies that may occur in individuals with familial MTC. This includes a history of unexpected sudden death, which should raise the suspicion of occult phaeochromocytoma.

- The initial evaluation of patients with suspected MTC includes US of the thyroid, FNAC and a baseline value for calcitonin, which may confirm the diagnosis and can indicate the likelihood of remission and extent of disease.

- In all cases at least one 24-hour urine sample assayed for catecholamines and nor/metanephrines or plasma nor/metane-phrines is required to exclude phaeochromocytoma, and a serum calcium to exclude hyperparathyroidism. These tests must be performed in all MTC patients prior to neck surgery even in the absence of a positive family history or symptoms.

- In all confirmed cased of MTC, RET mutation analysis to establish the possible genetic basis for the disease within an individual or kindred, should be performed even in the absence of a positive family history.

- Patients with established MTC should undergo a minimum of total thyroidectomy and central compartment node dissection, the inferior limit of the dissection being the inominate artery (levels VI and VII).

- Prophylactic surgery should be offered to disease-free carriers of germ line RET mutations, identified by genetic screening. The possibility of future surgery should be discussed with parents before testing children. In ideal circumstances these individuals would be expected to have CCell Hyperplasia $(\mathrm{CCH})$ rather than MTC but in many cases, by the time of presentation the transition from $\mathrm{CCH}$ to MTC will have occurred. This will depend upon the genotype and the age of the patient. Basal calcitonin levels indicate the likelihood of MTC \pm node metastases. It is important to distinguish the need for therapeutic surgery from prophylactic surgery.

- Lifelong follow-up is recommended.

- If expertise is not available within the primary clinical team, the patient should be offered genetic counseling and referred to the clinical genetics service.

- Patients with no special clinical features should be tested first for RET mutations in exons 10 and 11; if these are negative, for exons 13-16. Failure to screen exons 13-16 constitutes an incomplete test.

\section{3- Surgical management of anaplastic thyroid cancer (British Thyroid Association guidelines 2015):}

- Initial assessment should focus in identifying the small proportion of patients with localised disease and good performance status, that may benefit from surgical resection and other adjuvant therapies.

- The surgical intent should be gross tumour resection and not merely an attempt at debulking.

- Tumours that are small and intra-thyroidal or involve easily excised structures should be treated by total thyroidectomy, therapeutic lymph node dissection and where extra-thyroidal invasion is present, en bloc resection.

- Consideration of elective tracheostomy may be necessary in cases of advanced local disease. Although this procedure may avoid asphyxia and avert impending death, it may also prolong suffering and is often not in the patient's best interests.

- If a patient is being considered for radical surgery, EBRT or chemoradiotherapy and has swallowing difficulties, consideration should be given to gastrostomy placement.

\section{4- Surgical management of hyperthyroidism (ATA guidelines 2016):}

- Surgical options for those with hyperthyroidism include hemithyroidectomy for toxic adenoma or total thyroidectomy for toxic multinodular goiter or Graves disease.

- Patients who may benefit from surgery include those who cannot tolerate or are non-compliant with antithyroid medication, or have absolute or relative contraindications or aversion to radioactive 
iodine (RAI). Individuals desiring return to normal thyroid func-tion sooner than can be achieved with RAI may also consider thyroidectomy.

- It is recommended that before surgery hyperthyroid patients receive antithyroid medication, propanolol, and potassium iodide especially for patients with Graves disease. The patient should be rendered euthyroid and have a resting heart rate less than 80. Potassium iodide or Lugol solution has the potential benefit of decreasing the thyroid gland vascularity, and minimizing glandular hemorrhage during surgery. This can be administered in 1 to 2 lingual drops 7 to 10 days before surgery. Occasionally, corticosteroids may be necessary in medically refractory Graves disease patients.

\section{5- Surgical management of substernal goiter (Brit- ish Thyroid Association guidelines 2015):}

It is generally accepted that most benign SSGs can be removed through a cervical incision. For the remaining lesions not amenable for removal through a cervical approach, the authors use a ministernotomy, which is performed in conjunction with thoracic surgery. They involve the thoracic surgery service pre-operatively for possible sternotomy on patients with posterior mediastinal goiters, those goiters with extension below the level of the aortic arch, and known malignancy in the chest. In addition, a sternotomy has been recommended for the extraction of ectopic goiters.

Anatomically, one must recognize the potential anterior displacement of the RLN by a posterior mediastinal goiter. Prior knowledge of this allows the surgeon to anticipate the location of the RLN during surgical dissection. Additional surgical exposure is gained by positioning the patients' head in neck extension allowing for a cephalad displacement of the SSG. This facilitates improved delivery and visualization of the goiter.

\section{6- Surgical management of nodular goiter (ATA guidelines 2017):}

For patients with associated risk factors, the ATA suggests thyroid lobectomy as an initial treatment. Following lobectomy, intraoperative frozen histopathologic analysis positive for carcinoma requires a total thyroidectomy and possible central node dissection if gross nodal metastasis is identified. If the pathologist defers diagnosis until permanent sectioning, all patients with malignancy except those with a single focus or subcentimeter disease should undergo completion thyroidectomy. Completion thyroidectomy is usually performed in the first month following the initial procedure.
Scenarios that may benefit from a total thyroidectomyrather than lobectomy include (1) individuals with tumors greater than $4 \mathrm{~cm}$ and cytologic atypia, (2) FNAB "suspicious for papillary carcinoma," (3) patients with family history of thyroid carcinoma, and (4) childhood radiation exposure caused by increased risk of malignancy in these clinical settings.

Post-operative assessment: During the postoperative period all patients were carefully assessed for the clinical symptoms and signs of complications especially:

- Hypoparathyroidism: Diagnosed by symptoms and signs of hypocalcaemia including numbness, parasthesia and positive Chvostek sign and confirmation by an assay of serum calcium and phosphorus.

- Recurrent laryngeal nerve injury: Was checked by routine inspection of vocal folds during recovery from anaesthesia or indirect laryngoscopy in case of voice abnormalities, dyspnea or stridor post-operatively.

- Post-operative bleeding: Assessed through the drain.

- Seroma and wound infection.

- Hypothyroidism.

- Hospital stay.

\section{Results}

Table (1): Demographic data of the studied patients.

\begin{tabular}{cl}
\hline Variables & \multicolumn{1}{c}{$\mathrm{n}=60$} \\
\hline Age (years): & $39.18 \pm 11.75$ \\
Range & $(15-63)$ \\
Sex: & \\
Male & $11(18.3 \%)$ \\
Female & $49(81.7 \%)$ \\
\hline
\end{tabular}

Table (2): History of thyroid diseases and thyroid therapy of the studied patients.

Frequency (percentage)

\begin{tabular}{ll}
\hline History of: & \\
Toxic manifestation & $17(28.3 \%)$ \\
Anti-thyroid medication & $15(25 \%)$ \\
Iodine deficiency & $9(15 \%)$ \\
Endemic goiter & $7(11.7 \%)$ \\
Family history of thyroid disease & $5 \quad(8.3 \%)$ \\
Neck irradiation & 0 \\
Previous thyroid operation & 0 \\
\hline
\end{tabular}


Table (3): Vital signs in the studied patients.

\begin{tabular}{ll}
\hline & Mean \pm SD \\
\hline Heart rate (beat/ minute) & $78.78 \pm 7.03$ \\
Temperature $\left({ }^{\circ} \mathrm{C}\right)$ & $370.03 \pm 0.25$ \\
Systolic blood pressure $(\mathrm{mmHg})$ & $123.45 \pm 15.09$ \\
Diastolic blood pressure $(\mathrm{mmHg})$ & $81.09 \pm 6.34$ \\
Respiratory rate (cycle/ minute) & $19.91 \pm 0.92$ \\
\hline
\end{tabular}

Table (4): Thyroid examination in the studied patients.

\begin{tabular}{ll}
\hline & Frequency (percentage) \\
\hline Inspection: & \\
Unilobar thyroid enlargement & $12(20 \%)$ \\
Bilobar thyroid enlargement & $48(80 \%)$ \\
Palpation: & \\
- Goiter & \\
Diffuse & $4(6.7 \%)$ \\
Nodular & $56(93.3 \%)$ \\
Solitary & $13(21.7 \%)$ \\
Multinodular & $43(71.7 \%)$ \\
- Consistency: & \\
Soft & $5(8.3 \%)$ \\
Firm & $55(91.7 \%)$ \\
\hline
\end{tabular}

Table (5): Pre and post-thyroidectomy thyroid functions.

\begin{tabular}{lccc}
\hline & Pre-thyroidectomy & Post-thyroidectomy & $p$-value \\
\hline TSH & $1.26 \pm 0.76$ & $4.31 \pm 1.66$ & 0.00 \\
Free T3 & $1.96 \pm 0.52$ & $1.01 \pm 0.36$ & 0.01 \\
Free T4 & $0.93 \pm 0.23$ & $0.61 \pm 0.21$ & 0.00 \\
\hline
\end{tabular}

Table (6): Findings on neck ultrasonography of the studied patients.

\begin{tabular}{ll}
\hline Findings & Frequency (percentage) \\
\hline Multiple nodules: & \\
$\quad$ Right lobe & $4(6.7 \%)$ \\
$\quad$ Left lobe & 0 \\
Bilateral & $34(56.7 \%)$ \\
Single nodule: & $12(20 \%)$ \\
$\quad$ Right & $4(6.7 \%)$ \\
$\quad$ Left & $6(10 \%)$ \\
Diffuse thyroid enlargement & $11(18.3 \%)$ \\
Presence of lymphadenopathy & $4(6.7 \%)$ \\
Presence of retrosternal extension &
\end{tabular}

Table (7): Findings of fine needle aspiration cytology in the current study.

\begin{tabular}{lc}
\hline & Frequency (percentage) \\
\hline Not done & $19(31.7 \%)$ \\
Simple nodular goiter & $20(33.3 \%)$ \\
Colloid goiter & $11(18.3 \%)$ \\
Follicular adenoma & $8(13.3 \%)$ \\
Hyperplasia & $2(3.3 \%)$ \\
\hline
\end{tabular}

Table (8): Types of thyroidectomy in the current study.

\begin{tabular}{lc}
\hline Types of thyroidectomy & Frequency (percentage) \\
\hline Total thyroidectomy & $43(71.7 \%)$ \\
Subtotal thyroidectomy & $10(16.7 \%)$ \\
Unilateral lobectomy and isthmusectomy & $7(11.7 \%)$ \\
\hline
\end{tabular}

Table (9): Histopathological findings in the study.

\begin{tabular}{ll}
\hline Findings & Frequency \\
\hline Colloid goiter & $21(35 \%)$ \\
Hyperplasia & $17(28.3 \%)$ \\
Follicular adenoma & $7(11.7 \%)$ \\
Multinodular goiter & $4(6.7 \%)$ \\
Simple nodular goiter & $3(5 \%)$ \\
Fibroepithelial nodules & $3(5 \%)$ \\
Controlled toxic goiter & $2(3.3 \%)$ \\
Hashimoto thyroiditis & $2(3.3 \%)$ \\
Papillary carcinoma & $1(1.7 \%)$ \\
\hline
\end{tabular}

Table (10): Post-operative complications in the current study.

\begin{tabular}{lc}
\hline Complications & Frequency (percentage) \\
\hline Hoarseness of the voice & $18(30 \%)$ \\
Choking & $16(26.7 \%)$ \\
Injury of recurrent laryngeal nerve & $5(8.3 \%)$ \\
\hline
\end{tabular}

Table (11): Post-operative complications based on type of thyroidectomy in the current study.

\begin{tabular}{lccc}
\hline Complications & $\begin{array}{c}\text { Total } \\
(\mathrm{n}=43)\end{array}$ & $\begin{array}{c}\text { Suntotal } \\
(\mathrm{n}=10)\end{array}$ & $\begin{array}{c}\text { Unilobar } \\
(\mathrm{n}=7)\end{array}$ \\
\hline Hoarseness of the voice & $13(30.2 \%)$ & $4(40 \%)$ & $1(14.3)$ \\
Choking & $12(27.9 \%)$ & $4(40 \%)$ & 0 \\
Injury of recurrent laryngeal nerve & $5(11.6 \%)$ & 0 & 0 \\
\hline
\end{tabular}

Table (12): Duration of surgeon experience and incidence of complications.

\begin{tabular}{lllll}
\hline Chocking & $\begin{array}{c}\text { Hoarseness } \\
\text { of voice }\end{array}$ & $\begin{array}{c}\text { RLN } \\
\text { injury }\end{array}$ & $\begin{array}{c}\text { Frequency } \\
\text { (percentage) }\end{array}$ & $\begin{array}{c}\text { Duration of } \\
\text { experience }\end{array}$ \\
\hline $10(29.4 \%)$ & $12(35.29 \%)$ & $3(8.8 \%)$ & $34(56.7 \%)$ & $2-5$ years \\
$5(31.4 \%)$ & $4(25 \%)$ & $2(12 \%)$ & $16(26.7 \%)$ & $5-10$ years \\
$2(20 \%)$ & $2(20 \%)$ & $0 \%$ & $10(16.7 \%)$ & $>10$ years \\
\hline
\end{tabular}

Table (13): Types of goiter based on type of thyroidectomy.

\begin{tabular}{|c|c|c|c|}
\hline Type of goiter & Neck US & FNAC & Type of thyroidectomy \\
\hline $\begin{array}{l}\text { - Controlled toxic } \\
\text { goiter }(n=20)\end{array}$ & $100 \%$ & $8(40 \%)$ & $\begin{array}{l}\cdot 15(75 \%) \text { had total } \\
\text { thyroidectomy } \\
\cdot 3(15 \%) \text { had subtotal } \\
\text { thyroidectomy } \\
\cdot 2(10 \%) \text { had unilateral } \\
\text { thyroidectomy }\end{array}$ \\
\hline $\begin{array}{l}\text { - Single nodular } \\
\text { goiter }(n=12)\end{array}$ & & $12(100 \%)$ & $\begin{array}{l}\cdot 7(58.3 \%) \text { had total } \\
\text { thyroidectomy } \\
\text { - } 1(8.3 \%) \text { had subtotal } \\
\text { thyroidectomy } \\
\cdot 4(33.3 \%) \text { had unilateral } \\
\text { thyroidectomy }\end{array}$ \\
\hline $\begin{array}{r}\text { Multinodular } \\
\text { goiter }(\mathrm{n}=28)\end{array}$ & & $21(75 \%)$ & $\begin{array}{l}\cdot 21(75 \%) \text { had total } \\
\text { thyroidectomy } \\
\cdot 6(21.4 \%) \text { had subtotal } \\
\text { thyroidectomy } \\
\text { - } 1(3.6 \%) \text { had unilateral } \\
\text { thyroidectomy }\end{array}$ \\
\hline
\end{tabular}




\section{Discussion}

Surgical management is recommended for goiters with compressive symptoms. Symptoms of dyspnea, orthopnea, and dysphagia are more commonly associated with thyromegaly, in particular, substernal goiters.

Surgey is also recommended for bad cosmosis (on patient demand).

Pre-operative assessement with neck ultrasound, thyroid function tests, laryngoscopy (for assessement of vocal cord mobility), and FNAC (if of suspicious criteria) is necessary.

Pre-operative Fine Needle Aspiration Cytology (FNAC) was done in $41(68.3 \%)$ patients.

Treatment modalities for the surgical management of goiter include lobectomy, sub-total thyroidectomy, near-total thyroidectomy and total thyroidectomy.

Total thyroidectomy was associated with more post-operative complications and less reccurance rates than subtotal thyroidectomy and unilateral lobectomy. Most of the complications were transient and showed dramatic response with medical treatment.

Post-thyroidectomy complications were found to be associated with the surgeon's age of experience.

All patients should receive post-thyroidectomy thyroid replacement therapy in the form of Lthyroxine (except those who were subjected to unilateral lobectomy).

Post-operative assessement should include vocal cord mobility assessement, serum calcium measurement and regular follow-up of thyroid function tests.

Follow-up thyroid function tests have to be performed regularly and adjustment of replacement therapy must be done accordingly.

Histopathological examination postthyroidectomy is mandatory.

When comparing our surgical management strategy of thyroid diseases with standard guidelines, we noticed that:

1- Regarding controlled toxic goiter:

- Neck ultrasound was done in $100 \%$ of cases with no difference with guidelines.
- FNAC was done in $40 \%$ of cases (only suspicious cases as guidelines had recommended) with difference with guidelines about $20 \%$. This difference is due to many causes as; FNAC is expensive and not available at our hospital for free.

- Regarding type of operation performed:

- $75 \%$ had total thyroidectomy.

- $15 \%$ had subtotal thyroidectomy.

- $2 \%$ had unilateral thyroidectomy and isthmusectomy.

- 0\% had near-total thyroidectomy.

No difference with standard guidelines regarding type of operation was noticed except that neartotal thyroidectomy was not performed in any case.

2- Regarding solitary nodular goiter:

- Neck ultrasound was done in $100 \%$ of cases with no difference with guidelines.

- FNAC was done in $100 \%$ of cases with no difference with guidelines.

- Regarding type of operation performed:

- 58.3\% had total thyroidectomy.

- $8.3 \%$ had subtotal thyroidectomy.

- 33.3\% had unilateral lobectomy.

Difference with guidelines was found in 55\% of cases in whom total or subtotal thyroidectomy was performed in spite that unilateral lobectomy was the recommemded operation by standard guidelines. This difference was mainly due to the fair of histological surprise post-operatively (no intraoperative frozen section biopsy is available at our hospital), and need for completion thyroidectomy which is very difficult and risky.

3- Regarding multi-nodular goiter:

- Neck ultrasound was done in $100 \%$ of cases with no difference with guidelines.

- FNAC was done in $75 \%$ of cases (suspicious cases) no difference with guidelines.

- Regarding type of operation performed:

- 75\% had total thyroidectomy.

$-21.4 \%$ had subtotal thyroidectmoy, and

- $3.6 \%$ had unilateral lobectomy.

No major difference with standard guidelines was noticed.

\section{4- Regarding malignant goiter:}

Only one case of malignant goiter was encountered during the study period and was diagnosed 
as post-operative histological surprise, so no comparison with standard guidelines is possible.

\section{Conflicts of interest:}

No conflict of interest has been declared.

\section{References}

1- ACUN, et al.: 2004; EL-BUSHRA et al., 2009.

2- British Thyroid Association. Guidelines for the management of thyroid cancer, 2007.

3- CATZ B. and PERZIK S.L.: Total thyroidectomy in the management of thyrotoxic and euthyroid Grave's disease. Am. J. Surg., 118: 434-9, 1969.

4- HARNESS J.K., FUNG L., THOMPSON N.W., et al Total thyroidectomy: Complications and technique. World J. Surg., 10: 781-6, 1986.
5- HEDAYATI N., McHENRY C.R.: The clinical presentation and operative management of nodular and diffuse substernal thyroid disease. Am. Surg., 68: 245-51, 2002.

6- KHADRA M., DELBRIDGE L., REEVE T.S., et al.: Total thyroidectomy: Its role in management of thyroid disease. Aust. N. Z. J. Surg., 62: 91-5, 1992.

7- LIU Q., DJURICIN G. and PRINZ R.A.: Total thyroidectomy for benign thyroid disease. Surgery, 123: 2-7, 1998.

8- MATTIOLI, et al., 1996; BAKHEIT, et al., 2008; EL BUSHRA, et al., 2009.

9- REEVE T.S., DELBRIDGE L., COHEN A., et al.: Total thyroidectomy: The preferred option for multinodular goiter. Ann. Surg., 206: 782-6, 1987.

10- WALDSTROM, et al.: 1998; ACUN, et al., 2004; SALMAN \& OMER, 2007. 


\section{التقييم الإستقبالى لإستراتيجية المعالجة الجراحية

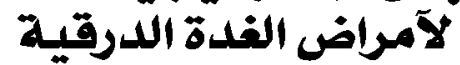 فى مستشفيات جامعة آسيوط الفيل}

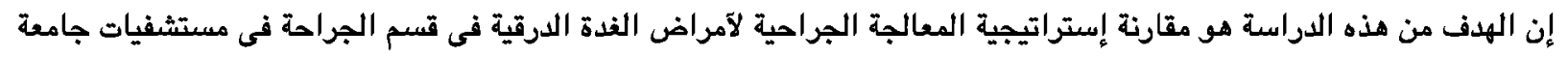

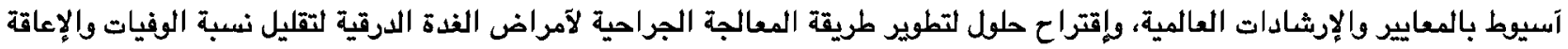
الناتجة عن هذه الآمراض وجعلها تتناسب مع معايير ونسب الشئفاء العاد العالمية.

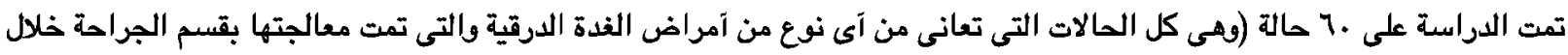

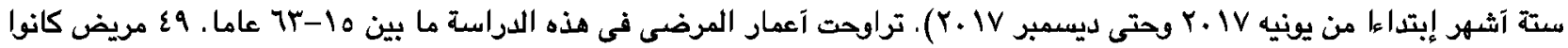

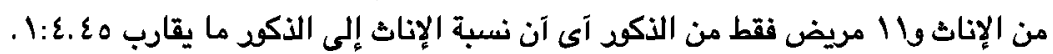

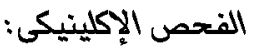

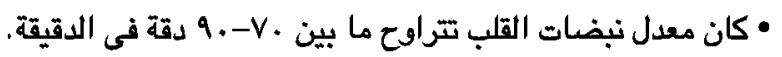

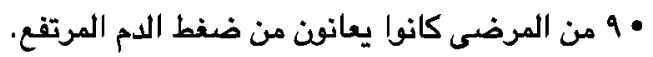
• • ع مريض كان يعانى من تضخم عقدى متعدل للفدة الدرقية من الجانبين الآيمن والآيسر.

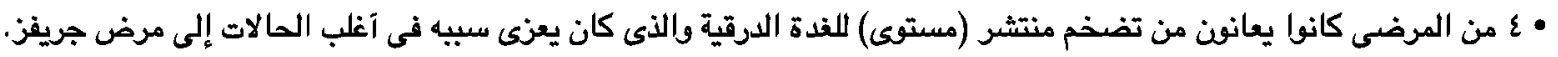

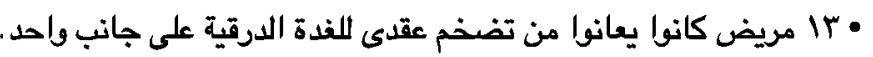

فوصوصات ما قبل الجراحة:

• خضع كل المرضى إلى آشعة تليفزيونية على الرقبة والتى آوضحت آنس آن:

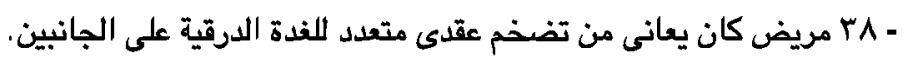
- 11 - مريض كان يعانى آيضا من تضخم بالغدد الليمفاوية.

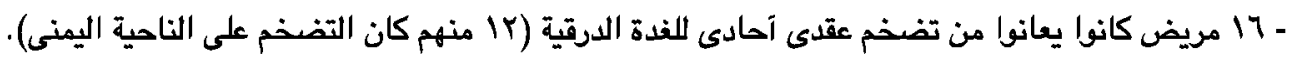
- 7 من المرضى كانوا يعانوا من تضخم منتشر (مستوى) للفدة الدرقية.

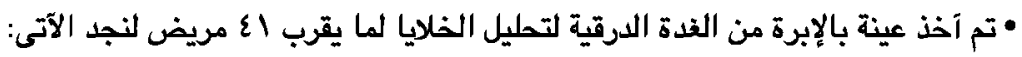
- I. - Tريض يعانى من تضخم عقدى بسيط للفدة الدرقية. - 11 - مريض يعانى من تضخم غروانى اللغدة الدرقية.

- 1 مرضى يعانوا من ودم جريبى اللغدة الدرقية (قد يكن حميد آوخبيث).

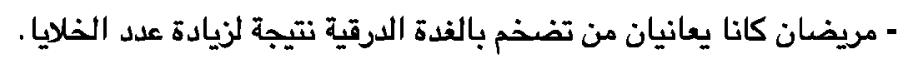

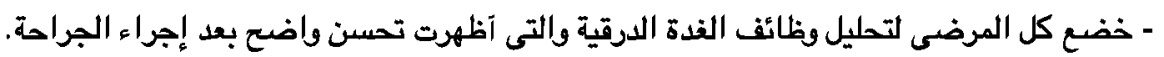

نوع العملية الجراحية والمضاعفات الناتجة عنها:

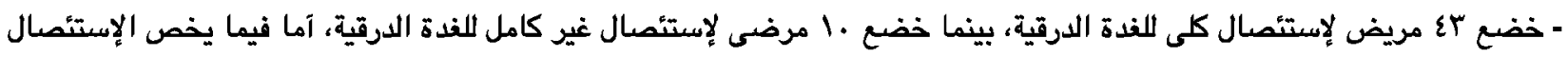

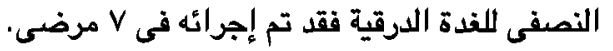

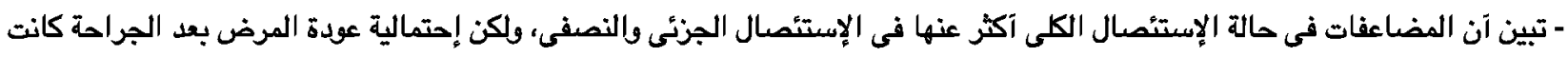
آقل مع الإستئصال الكلى اللغدة الدرقية. - تعرض العصب الحنجرى المرتجع إلى الإصابة في ه مرضئ.

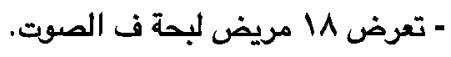
- آغلب هذه المضاعفات كانت مؤقتة وتحسنت مع العلاج. 